\title{
Sugarcane Breeding and Biotechnology to Feed the Emergent Sugarcane Biorefinery Industry
}

\author{
Paul H. Moore • Ray Ming
}

Received: 7 March 2011 / Accepted: 8 March 2011 /Published online: 5 April 2011

(C) Springer Science+Business Media, LLC 2011

This special issue of Tropical Plant Biology features review articles on issues emerging with the production, processing, and improvement of sugarcane, the world's most industrialized tropical crop. The fundamental reason for large scale industrialization of sugarcane is that the plant has unique attributes contributing to high productivity with minimal inputs, across a range of tropical environments. Sugarcane produces the largest quantity of biomass of any annually harvested field crop making it a candidate crop on which to base a biorefinery industry. The 2008 FAO estimation was that 1.74 billion tonnes of sugarcane stalks were harvested and transported to local mills for crushing and processing. Production of large quantities of relatively inexpensive biomass, near mills capable of processing the material into a range of industrial feedstocks, has parallels to petroleum industry refineries except that petroleum hydrocarbon is not a renewable resource while sugarcane carbohydrate is. This difference in sustainability is driving the development of new science and technologies that are changing the sugarcane industry.

The collection of papers in this issue begin with a brief 30 year history of Brazil's bioethanol program and a perspective on the political, economic, sociological, and technology issues that have changed during this period to achieve success with ethanol and beyond, with greater

Communicated by: Paulo Arruda

P. H. Moore $(\bowtie)$

Hawaii Agriculture Research Center,

Kunia, HI, USA

e-mail: PMoore@harc-hspa.com

R. Ming

Department of Plant Biology, University of Illinois at UrbanaChampaign,

Urbana, IL 61801, USA sustainability in all areas (Arruda 2011). In addition to the ethanol derived from the sugar stored in the sugarcane stalk, additional energy is currently derived from burning the plant fiber to generate electricity. New technologies under development in partnerships between the sugarcane industry and large petroleum and biotechnology companies will allow for the use of sugarcane fiber as a feedstock for new industries producing advanced biofuels and products previously manufactured from petroleum.

Currently, bioethanol replaces around $30 \%$ of the gasoline consumed in Brazil and the demand for bioethanol is projected to more than double in the next 10 years (Arruda 2011). This demand will be met with a comparable increase in the mass of sugarcane produced by breeding for greater productivity and expanding the area for sugarcane farming. Expansion of the sugarcane industry into areas not previously devoted to sugarcane cultivation will require new cultivars adapted to a wide range of poor environments. In other words, the industry will need cultivars having greater tolerance to abiotic stresses of toxic metals, drought, salinity, temperature, and soil nutrients (Azevedo et al. 2011; de Carvalho et al. 2011).

Production of new stress-tolerant cultivars will depend on developing an increased understanding the biochemical and physiological responses of sugarcane to abiotic stresses (Azevedo et al. 2011) and modifying plant structure such as increasing the root functions of the plant (Matsuoka and Garcia 2011). Both of these areas have received little attention, yet the natural variation existing between the progenitor species (Saccharum officinarum and Saccharum spontaneum) indicates that it should be possible to quickly develop environmentally adapted cultivars as the basis for sustainable agriculture and a second green revolution (Matsuoka and Garcia 2011). An additional area promising for minimizing the costs of production and to make 
sugarcane production more sustainable will be to breed and select not only cultivars of sugarcane, but also endophytic bacteria of sugarcane for biological nitrogen fixation (BNF) (de Carvalho et al. 2011). Although BNF is well studied between legumes and Rhizobium bacteria, much less is known about BNF form the association of endophytic bacteria with grasses, even though from a world food supply perspective the cereal grasses provide a majority of calories for human consumption. Studies on the genetic controls of establishing BNF in sugarcane can prove beneficial for sugarcane culture and may be extended to other important crops (de Carvalho et al. 2011).

Sugarcane breeding and selection programs have existed for just over 100 years, based on using superior parental lines to produce large progeny populations from which the best performing hybrids were obtained through vigorous selection. All advances have been made without any significant information on sugarcane genetics or genomics. This situation is changing with the development of molecular markers linked to agronomic traits and to each other to produce molecular marker genetic maps and QTL linkage data. Genomic analysis has now grown to include transcriptome analysis and functional genomics (Manners and Casu 2011). Such analyses have been used to analyze the genetics of sucrose accumulation which will lead to models of plant function, molecular breeding, and genetic modification (Manners and Casu 2011). However, one must first prove the safety of the genetically modified plant to the environment and the ability to contain the transformed gene in order to obtain regulatory approval to grow the crop. This requires extensive data on all aspects of the plant including its basic biology, interactions with other organisms, effect on biota, modification on soil characteristics, and uses for food, feeds or other uses as is reported in the enclosed paper by Cheavegatti-Gianotto et al. (2011). Although written for obtaining regulatory approval in Brazil, this paper should be useful as a reference for regulatory applications elsewhere.

The collection papers in this special issue report thoughtful analyses on various aspects of developing superior sugarcane varieties and technologies for the development of a sugarcane biorefinery industry.

\section{References}

Arruda P (2011) Perspective of the sugarcane industry in Brazil. Trop Plant Biol 4:3-8

Azevedo RA, Carvalho RF, Cia MC and Gratão PL (2011) Sugarcane under pressure: an overview of biochemical and physiological studies of abiotic stress. Trop Plant Biol 4:42-51

Cheavegatti-Gianotto A, de Abreu HMC, Arruda P, Bespalhok Filho JC, Burnquist WL, Creste S, di Ciero L, Ferro JA, de Oliveira Figueira AV, de Sousa Filgueiras T, Grossi-de-Sá MdF, Guzzo EC, Hoffmann HP, de Andrade Landell MG, Macedo N, Matsuoka S, de Castro Reinach F, Romano E, da Silva WJ, de Castro Silva Filho M and César Ulian E (2011) Sugarcane (Saccharum X officinarum): a reference study for the regulation of genetically modified cultivars in Brazil. Trop Plant Biol 4:6289

de Carvalho TLG, Ferreira PCG and Hemerly AS (2011) Sugarcane genetic controls involved in the association with beneficial endophytic nitrogen fixing bacteria. Trop Plant Biol 4:31-41

Manners JM and Casu RE (2011) Transcriptome analysis and functional genomics of sugarcane. Trop Plant Biol 4:9-21

Matsuoka S and Garcia AAF (2011) Sugarcane underground organs: going deep for sustainable production. Trop Plant Biol 4:22-30 